\title{
Martín Heidegger: crítica al concepto hegeliano de experiencia (primera parte)
}

\section{Rodolfo García Aguilar}

Licenciado en Filosofía. Tutor de la Cátedra de Filosofía, Escuela de Ciencias Sociales y Humanidades de la Universidad Estatal a Distancia. Correo electrónico: rga3cr@yahoo.com

\author{
Recibido: Febrero 2014 • Aceptado: Mayo 2014
}

\section{RESUMEN}

\begin{abstract}
El presente trabajo tiene como objetivo retomar la temática expuesta por Martín Heidegger, en su artículo "El concepto hegeliano de experiencia", para rescatar sus reflexiones en el campo de la ontología. Se propone abrir nuevamente la discusión en un mundo metafísico donde se consolida lo que el autor llama "la imagen del mundo", y donde se considera esta, erróneamente, como la única forma de enfrentarse y apoderarse de la realidad. Guillermo Federico Hegel, según Heidegger, es uno de los pensadores que más contribuyó a la creación de esta nueva "imagen del mundo" la cual debate, razón por la cual consideraba a Hegel el último gran metafísico griego.
\end{abstract}

Palabras clave: Heidegger, Hegel, experiencia, imagen del mundo, ser.

\section{ABSTRACT}

This work aims to resume the theme expounded by Martin Heidegger, in his article "The Hegelian concept of experience" to rescue their reflections in the field of ontology. It is proposed to open up the discussion again in a metaphysical world where what the author calls "the image of the world," consolidates and where this is considered, erroneously, as the only way to face and take over the reality. Wilhelm Friedrich Hegel, according to Heidegger, is one of the thinkers who most contributed to the creation of this new "world view" that he debates and its why he considerate Hegel as the last great metaphysical Greek.

Key words: Heidegger, Hegel, experience, world image, being.

\section{Introducción}

Usualmente se divide el desarrollo del pensamiento de Martín Heidegger (1889-1976) en tres temáticas: 1) el ser como fundamento, dentro de la cual se sitúan obras como El Ser y el tiempo (1927), ¿Qué cosa es la metafísica? (1929), El ser como verdad y fundamento; 2) la temática del subjetivismo como nihilismo, donde se valora el tema de la historia; aquí se ubican obras como Holzwege y Nietzsche (1953) 3) la temática de la filosofía del lenguaje, en que se ubican obras como ¿Qué significa pensar? (1954).

En nuestro caso particular, nos ubicamos en el segundo eje temático con el artículo "El concepto hegeliano de experiencia", escrito entre los 
años 1942 y 1943 y publicado como parte de su libro Holzwege, obra donde se analiza y comenta las ideas fundamentales de Guillermo Federico Hegel de su libro La fenomenología del espíritu, con el objetivo de demostrar cómo la postura hegeliana respalda su teoría de la formación en la filosofía occidental de una imagen del mundo.

La importancia de esta obra radica en que es la primera vez que Heidegger se enfrenta a Hegel y trata de demostrar la inversión que se da a ciertos conceptos metafísicos que permiten consolidar el marco filosófico dentro del cual se construye y concluye la metafísica en Occidente.

La metodología de exposición del presente trabajo consiste, en un primer momento, exponer sistemáticamente la posición de Heidegger con respecto a la metafísica actual, para ubicarnos en el marco conceptual que Heidegger quiere reconstruir; de seguido escoger y exponer, de algunos capítulos del artículo "El concepto hegeliano de experiencia", la versión de Heidegger sobre Hegel y señalar cuáles son las críticas directas al pensamiento de Hegel, para luego concluir críticamente si dicha posición efectivamente demuestra la propuesta heideggeriana o si no logra superar la postura de Hegel.

El presente trabajo se divide en dos partes: la primera abarca hasta el capítulo 8 del artículo dicho; una segunda parte hasta el artículo 16, para finalmente concluir con la totalidad de estos. Cada artículo culminará con una serie de conclusiones provisionales sobre el desarrollo de la exposición para concluir en una sola al final del último trabajo.

El presente trabajo no tiene por objetivo construir o destruir un mundo conceptual, cosa que está totalmente fuera del alcance de quien escribe, sino más bien extraer conclusiones de una confrontación entre dos de los grandes pensadores de la filosofía alemana y evidenciar que dicha confrontación todavía hoy es tema de reflexión y de vigencia filosófica.

¿Es el concepto de conciencia hegeliano estático, en el sentido de subiectum, de creador de la realidad a partir de su manifestación como verdad?, ¿es el ser de Heidegger la manifestación por sí, al que la metafísica occidental ha dejado de ser sensible, y al cual tiene que recurrir nuevamente para encontrar su esencia?

Creo, a modo de hipótesis, que son modos de ser dentro de la realidad, una captada dentro del movimiento de la conciencia, que es histórica, y otra, una apreciación histórica que debe ser sensibilizada dentro de la conciencia del Da-Sein.

\section{Propuesta filosófica del autor}

La posición filosófica heideggeriana ${ }^{1}$ se puede resumir de la siguiente manera:

a) Todo fenómeno del Ser, en sentido estricto, es horizonte, más precisamente, la unidad de los horizontes de la temporalidad. Ser es la unidad de esos horizontes con sus respectivos éxtasis, es la temporalidad como verdad originaria.

b) Los horizontes son los esquemas de la verdad. El esquema de la verdad, del Ser en general, es la unidad articulada de los esquemas primarios de los diferentes éxtasis.

c) De esta unidad esquemática se derivan dos modos de verdad: la existencia del Da-sein y el estar-presente de la cosa, como dos modos del estar patente la independencia del ente respecto del Ser.

d) Tanto la unidad esquemática del Ser, en general, como del Ser del Da-sein y la del ser de las cosas están articuladas por la distinción entre el modo del Ser y el ser-algo.

1. "Desde hace 60 años he tratado de comprender lo que es la filosofía y no de proponer una"... "Hoy día lo que se llama filosofía no es raramente otra cosa que una calcomanía de ideologías técnicas, que toman en préstamo los métodos propios de la física y la biología. Eso no es ya una interrogación filosófica auténtica" (De Towarnichi y Palmier, 1981). 
e) Con base en esta distinción temporal de la verdad, es posible la distinción entre Ser (verdad) y el ente. ${ }^{2}$

Lo que originalmente significó y se interpretó como brotar del mundo e imponente poderío, el fainesai, el aparecer del mundo, la epifanía del mundo, se convierte ahora, en la época moderna, con la ayuda de la metafísica, en cosas presentes y manifiestas materialmente.

El ojo al ver, en su forma original, intuía el proyecto del brotar y del sostenerse. Ahora constituye algo que puede mirarse simplemente, observarse y explorarse con curiosidad, con admiración.

En los comienzos griegos de la exégesis del ser, se desarrolló un dogma que no solo declara superflua la pregunta que interroga por el sentido del Ser, sino que, además, sanciona la omisión de la pregunta.

La metafísica moderna, pasando por Kant, Hegel y Nietzsche, no es tal metafísica, sino solo física, referida específicamente a la fisis, y en algunos casos ni siguiera llega al plano de la fiscis.

En este sentido, veamos cómo supuestamente Hegel ayuda a tal inversión y olvido del Ser, al presentar la conciencia como una realidad que no solo se basta a sí misma, sino que determina la realidad a partir de sí misma.

¿Será la posición de Hegel solamente un estudio de la fisis o más bien una metafísica del Ser, pero con alguna variante transcendental?

2. "Yo no hablo de una historia de la decadencia, sino solamente del Ser, en la medida en que se retira cada vez más en la relación del Ser con los griegos hasta que el Ser se vuelve una simple objetividad para la ciencia y actualmente un simple fondo de reserva para el dominio técnico del mundo... un retiro del ser..." (Entrevista con Richard Wisser, 1969).

\section{Desarrollo de los capítulos}

\section{Capítulo primero}

Del capítulo primero de la Fenomenología del espíritu, Heidegger retoma el papel de la filosofía. Reinterpreta, a la luz de Hegel, las nuevas implicaciones de una cita aristotélica: "Contempla como presente y (contempla) de suerte que lo que en éste (lo presente) predomina de suyo" (Aristóteles, traducido por Heidegger, 1960: 110).

Comenta el autor al respecto, en defensa de su tesis, que el predominar afecta al hacerse manifiesto, en el desocultamiento; la filosofía contempla lo presente en su presencia, el contemplar considera lo presente. El contemplar aspira frente a lo presente, de suerte que considera lo presente solo como tal.

En cambio, Hegel, por su lado, comenta la frase: "La filosofía es 'el real conocer' de lo que en verdad es" (citado por Heidegger, 1960: 111). En esta concepción hegeliana, lo verídicamente existente se ha puesto en claro como lo real, cuya realidad es el espíritu, cuya esencia descansa en la conciencia de sí mismo. En esta postura se ve cómo el pensar busca para sí el fundamentum absolutum, en la inconmovible certidumbre de lo por él pensado, es la autocertidumbre del saber.

De esta manera, siguiendo esta versión hegeliana, la filosofía moderna mora en la tierra de la conciencia de sí misma y exige llegar a tener certidumbre de su principio. Quiere cerciorarse del conocer con que supuestamente conoce absolutamente.

Lo absoluto para Hegel es espíritu, o sea, lo presente en sí mismo en la certidumbre del absoluto saberse. "El real conocer de lo existente como existente es ahora el conocer absoluto de lo absoluto en su absolutez" (Heidegger, 1960: 111).

\section{Capítulo segundo}

En este capítulo de la Fenomenología, Hegel se centra en el núcleo de la crítica del conocer: ya no se usará el nombre de filosofía, sino el de ciencia. 
Con esta posición, según Heidegger, la filosofía moderna llega a la consumación de su esencia, gracias a haber tomado posesión de su campo, el cual es la autocertidumbre del representar respecto de sí mismo y de lo por él representado; esto significa, saber, la autocertidumbre de la autoconciencia de su incondicionada esencia y ser absolutamente saber en ese saber.

Con la postura hegeliana, la esencia de la ciencia es ahora lo verdaderamente presente, el subiectum, el hipokeimenón de los griegos. El representar presenta el objeto al representarlo al sujeto, representación en la cual se presenta el sujeto como tal.

La representación es el rasgo fundamental del saber en el sentido de autoconciencia del sujeto. La representación es un modo esencial de presencia (parousía). En calidad de tal, o sea como presencia, es el ser de lo existente. La certidumbre, como saberse condicionado en sí, es decir, incondicionado, es la cualidad del ser (ousia) del sujeto. El ser sujeto del sujeto, es decir, la relación sujeto-objeto, es la subjetividad del sujeto. La subjetividad consiste en el saberse condicionado (Heidegger, 1960: 114).

Así, la esencia del sujeto es de tal índole que este, para ser sujeto, solo tiene que proporcionarse esa cualidad con el saber.

La subjetividad del sujeto, como absoluta autocertidumbre, es la ciencia. Lo existente (to $o n)$ es como existente ( $e$ on) si es a la manera del incondicionado saberse del saber.

Otro elemento interesante dentro de este análisis es el papel de la crítica. Heidegger afirma que, dentro de este contexto, la crítica toma el conocer como algo real, aunque no como lo real primero y decisivo. La crítica invoca algo verdadero, algo cierto para ella, cuya certidumbre tiene que existir aun aparte de la autocertidumbre absoluta de todo lo cierto.

Todo lo anterior se fundamenta en el capítulo siguiente, donde Hegel expone que lo absoluto es verdadero.

\section{Capítulo tercero}

Heidegger cita a Hegel:

Sólo lo absoluto es verdadero. Sólo lo verdadero es absoluto. Las proposiciones se ponen sin fundamentación. No cabe fundamentarlas porque ningún fundamentar alcanza a su fundamento. No alcanza nunca a su fundamento porque, como voluntad de fundamentar, se mantiene siempre fuera de su fundamento En ellas habla la voluntad de lo absoluto que en sí y para sí quiere estar ya en nosotros (Hegel, citado por Heidegger, 1960: 116).

Critica Heidegger que la certidumbre que se ha asegurado de su saber, en sí misma y ante sí misma, se ha retirado ya de todo aislado representar de objetos. Ya la certidumbre no necesita ni depende de objetos, para tener lo verdadero en ese depender; así, el saber, ahora, se deslinda de su antigua relación con los objetos.

El saber se absuelve de la unilateral vinculación a los objetos y el mero hecho de representarlos. La autocertidumbre es la absolución de sí misma, un saber desbocado relativamente anárquico, autoritario, y dentro de este proceso aparece la voluntad como legitimación de la conciencia.

\section{Capítulo quinto}

Hegel inicia la meditación hacia el reconocimiento de la necesidad misma de la exposición del saber aparente para realizar y hacer la esencia de lo absoluto, retomando para ello la temática de la ciencia y su relación con el representar del saber que aparece; la ciencia, al representar el saber que aparece, tiene que manifestarse mediante tal exposición.

$\mathrm{Su}$ aparecer consiste en que va demostrando lo que es; tal demostración se da en el representar natural, el cual sigue el saber que aparece (mediante la multiplicidad de sus fenómenos) y persigue la demostración; como es saber solo aparente, se desprende de la apariencia para terminar presentándose como verdadero saber.

La exposición del saber aparente lleva al representar natural por el camino que, pasando por 
el saber, llega a las puertas del saber absoluto: la exposición del saber aparente es el camino de la conciencia natural hacia la esencia.

El camino de la conciencia natural va a través de los fenómenos, es el camino de la experiencia que guía al representar natural en el dominio de la ciencia de la filosofía. Aquí el saber, que se manifiesta cuando es visto con los ojos del representar natural, se relaciona con lo que en cualquier momento cree tener ante sí.

Al respecto Heidegger critica:

Lo que se representa a la conciencia natural con el nombre de saber sólo aparente, que todavía tiene que conducir a lo verdadero, es mera apariencia. Sin embargo, hasta nuestros días, la filosofía cree que la fenomenología del espíritu es un itinerario, una descripción de viaje, que conduce a la conciencia cotidiana al conocer científico de la filosofía. Más lo que parece ser la fenomenología del espíritu así tomada, no lo es en su esencia. Pero esa apariencia no engaña así como así. Viene a raíz de su esencia, se impone antes de ésta y la encubre... (Heidegger, 1960: 122).

Volviendo a Hegel: el representar natural toma el saber aparente como meramente aparente, pero la representación es solo del saber que aparece. Es a este aparecer del saber a lo que se llama la verdad del saber.

La exposición de este saber que aparece, en su aparecer es él mismo, la ciencia; en el momento en que comienza la exposición, ya es ciencia.

Heidegger critica dicha posición aduciendo:

Pero la exposición no conduce en modo alguno al representar natural por el museo de las figuras de la conciencia, para despedirlo al final de la visita por una puerta especial que conduzca al saber absoluto. Antes bien, la conciencia, con el suyo, aunque no antes de su primer paso, despide a la conciencia natural, considerándola como incapaz de seguir la exposición. La exposición del saber que aparece, no es una marcha que la conciencia natural recorra. Pero tampoco es un camino que paso a paso se aleje de la conciencia natural para luego ir a parar en su curso a algún lugar del saber absoluto (Heidegger, 1960: 123).

\section{Capítulo sexto}

Heidegger critica la utilización de los nombres conciencia y saber, pues según su opinión, Hegel los emplea como sinónimos. Si son utilizados como sinónimos, entonces conciencia significa estar en estado de saber. De esta manera, el saber mismo notifica, presenta, determina el modo de ser como ser-sabido.

En el mundo hegeliano, ver se concibe como tener-ante-sí en el re-presentar. El representar se da tanto si el presente es algo percibido por los sentidos, como si es algo pensado, querido o sentido, independientemente de estos. Resume Heidegger la posición hegeliana:

El representar vislumbra de antemano, es captación de la visión, es "idea", pero en el sentido de la "perceptio". Se propone cada vez un presente como tal y lo rebasa, lo examina y lo pone a salvo. El representar domina en todos los modos de la conciencia (Heidegger, 1960: 124).

Se desprende de lo anterior que, según Hegel, el representar no es solamente un contemplar, ni ya un pensar en el sentido del concepto que juzga, sino que el representar se concentra de antemano en un haber-visto (co-agitat); en tal concentración está presente lo visto. La conscientia es la concentración en la presencia a la manera de la presencia de lo representado. Resume el autor: "El representar, como modo de haber visto, involucra el aspecto, la imagen en la presencia" (Heidegger, 1960: 124).

Ser-sabido, dentro de este contexto, significa estar presente en el involucrar desde el ser-representado. Lo existente, a la manera del saber, se llama sujeto, o sea, lo ya presente en todas partes $y$, en consecuencia, acompaña a toda conciencia.

Este estar presente, en el estado del re-presentado, significa presentarse en el saber como saber; es aparecer en el sentido directo de surgir en un desocultamiento. Es dentro de esta estructura que tiene sentido y funcionamiento la relación sujeto-objeto. Aquí, la conciencia legitima su propio proceder siguiendo sus propias reglas, leyes y ritmo. 
Dentro de esta lógica, la existencia de la conciencia es el aparecer, pero de suerte que el escenario del aparecer se forme en el aparecer y mediante este mismo. Lo cual se puede dar cuando la conciencia ha dominado el marco de referencia y es la referencia misma.

Hegel no nos habla de un saber que por primera vez se pone de manifiesto, sino de un representar en su aparecer, el saber que, directamente, no es sino lo que aparece.

La exposición representa, con el saber aparente, la conciencia existente considerada como existente, o sea, como saber real. Real en el sentido de la subjetividad del sujeto, que es el aparecer mismo, donde lo existente se expone como existente.

Heidegger resume dicha posición: "Exponer es ahora el sujeto como sujeto, lo aparente como aparente. La exposición del saber aparente es la ontología de la conciencia real como real" (Heidegger, 1960: 125).

En Hegel, la filosofía es el camino del representar expositivo, movimiento que deberá determinarse a base de la conciencia aparente como tal, o sea, del saber real que es la verdad del saber natural.

Por lo anterior, Hegel comienza la designación de la esencia de la exposición con la siguiente proposición: "La conciencia natural demostrará que es sólo concepto del saber, o saber no real" (Hegel, citado por Heidegger, 1960: 125). En otras palabras, lo natural no es lo real, y lo real no es lo natural: "Hegel no niega que la naturaleza sea algo real; pero sí enseña que no puede ser la realidad, el ser de lo existente. Además, Hegel tampoco dice en modo alguno que la naturaleza no sea sino concepto" (Heidegger, 1960: 126).

Heidegger reinterpreta ahora la sentencia hegeliana "lo real es lo verdaderamente existente", en el sentido de que el ens verum es, desde Descartes, el ens certum, lo que se sabe en la certidumbre, lo presente en el saber.

Pero, resulta ser que el ens certum sólo es verdaderamente sabido si es sabido qua ens. El esse del ens se representa propiamente, lo existente es sabido en su ser y lo real en su realidad. Aquí el saber real es el saber, que en todo momento y lugar representa lo existente en su realidad: lo aparente en su aparecer.

Pero el saber natural es el saber no real, eso quiere decir que este se revela como aquel saber que nunca representa lo existente como tal, sino que, en su representar, solo depende de lo existente.

Este representar natural de lo existente es ya en sí, y necesariamente ese representar general de la realidad de lo existente; la conciencia natural no repara en el ser, y aún así, debe tenerlo en cuenta.

Sigue criticando Heidegger que la conciencia natural no puede menos que representar concomitantemente en general el ser de lo existente, porque, sin la luz del ser, ni siquiera podría perderse en lo existente.

Por lo anterior Hegel considera que la conciencia natural es "sólo concepto del saber", porque es únicamente el representar de la realidad en términos generales e indeterminados, no es un saber que adquiere certidumbre de la realidad de lo real.

Aquí Hegel emplea el término concepto en su versión clásica, según la doctrina de la lógica, que determina el pensar natural en sus formas y reglas. Así, el concepto es la representación del algo en general, ese representar no comprende propiamente su representado.

Heidegger afirma que lo que Hegel denomina conciencia natural no coincide en nada con la conciencia sensible; por el contrario, el saber natural vive en todas las formas del espíritu, vive cada una de ellas a su manera.

Esta metafisica se hundió tan poco antes del positivismo de los siglos XIX y XX que, por el contrario, el mundo técnico moderno, en su pretensión incondicionada, no es otra cosa que la conciencia natural que, a la manera de su opinar, realiza la absoluta restaurabilidad, que se asegura a sí misma, de todo lo existente, en la incontenible objetización de todas y cada una de las cosas (Heidegger, 1960: 127).

Heidegger afirma que lo natural de la conciencia no descansa en lo sensible ni en lo perceptible por los sentidos, que es un perjuicio muy arraigado, sino que lo natural de la conciencia 
descansa en aquello que surge directamente de la conciencia, y así surgido, se le incorpora directamente, dadas las condiciones lógicas y epistemológicas que la conciencia ha logrado instaurar y reforzar a lo largo del camino de su supuesto ascenso. "De esta manera la conciencia natural absorbe también todo lo no sensible, sea lo asensible de lo racional y lógico, sea lo suprasensible de lo espiritual" (Heidegger, 1960: 128).

Lo que Heidegger quiere evidenciar es que la conciencia natural y el saber real son de hecho lo mismo: la conciencia, todavía no verdadera, coincide con el saber real, o sea, su verdad. Pero no por esta coincidencia son lo mismo.

La exposición del saber aparente, en su aparecer, desde la conciencia natural, duda. Este dudar pone entre paréntesis muchos modos del representar, pero solo para permanecer en la posición del punto de partida del cual sale.

El camino de la duda se limita a poner en claro que el dudar ya se puso en una seguridad que se tiene por fundamentum absolutum. Más la absolutez de ese fundamento absoluto no se pone en duda, ni se interroga, ni siguiera se lo menciona en su esencia (Heidegger, 1960: 128).

Los fundamentos del repensar estaban más elaborados en la época de Hegel, tanto así, que solo queda la necesidad de enunciación, y la nueva realidad salta del vacío ontológico a la realidad del espíritu, suplantando así el hipokeimenon de los orígenes del pensamiento; en la exposición absoluta del saber aparente, no se dan las condiciones para que la conciencia natural pueda volver a su verdad.

La filosofía inaugura, conceptualmente, la problemática de la primacía de la esencia o de la existencia y su consiguiente delimitación y autojustificación.

La historia de la conciencia hace surgir la conciencia misma en su aparecer. Esta historia es, según Hegel, "la historia de la formación de la conciencia misma en la ciencia". Hegel piensa en el aparecer de la conciencia aparente desde el completo aparecer en que la conciencia es ya la ciencia misma.
Según todo lo anterior, en la interpretación de Heidegger, Hegel denomina lo existente a lo que se torna objetivo a la conciencia en el representar directo. Objetivo es lo universal representado, sin tomar en cuenta al representar ni lo representado; estos quedan por fuera.

Dentro de esta concepción y como consecuencia lógica, el ser como nombre para lo llamado existente, en realidad es el nombre para lo que propiamente no es todavía en verdad lo verdadero y lo real.

Lo verdadero existente para Hegel es el ens actu, lo real, su actualitas, realidad, consistente en el saber de la certidumbre que se sabe a sí misma, es la conciencia de sí misma; solo esta puede ser toda la realidad. ${ }^{3}$

Heidegger, por el contrario, emplea el nombre de ser tanto para lo que Hegel, siguiendo a Kant, denomina objetidad y objetividad, como para lo que Hegel representa como lo verdaderamente real y lo llama realidad del espíritu.

La realidad de lo existente que desde los comienzos del pensamiento griego hasta la doctrina nietzcheana del eterno retorno de lo igual se produjo como verdad de lo existente, para nosotros no es sino un modo, bien que decisivo, del ser que en modo alguno aparece necesariamente sólo como presencia de lo presente (Heidegger, 1960: 132).

\section{Conclusión}

A modo de reflexión provisional de esta primera parte, que abarca los ocho primeros capítulos del artículo "El concepto hegeliano de

3. "En la introducción a las Lecciones sobre la historia de la filosofía (ed. Hoffmeister, t. I. p.240) dice Hegel: 'El primer universal es lo universal inmediato, es decir, el Ser. El contenido, el objeto es, por ende el pensamiento objetivo, el pensamiento que es. Hegel quiere decir con esto: el Ser es el ser pensado en forma pura de lo inmediatamente pensado, todavía sin referencia al pensar, el cual piensa lo pensado prescindiendo del escudriñamiento. La determinación de lo pensado en forma pura es la 'indeterminabilidad'; su escudriñamiento es la inmediatez..." "(Heidegger, 1969: 7). 
experiencia", se considera que, si bien Heidegger traduce y maneja perfectamente el lenguaje filosófico hegeliano, lo quiere interpretar dándole un giro que ni el propio Hegel hubiese aceptado.

No tiene razón Heidegger en la interpretación que quiere presentar sobre las reflexiones hegelianas, en cuanto a los distintos conceptos filosóficos y la forma como los relaciona.

La reflexión hegeliana, hasta el momento, es más dinámica, más dialéctica, más rica en cuanto al movimiento de la conciencia como referencia de la realidad, como captación de lo que se considera la verdad, aunque verdad de un momento, pues es un proceso de crecimiento y enriquecimiento.

Tendremos que ver el desarrollo de los otros capítulos para verificar si Heidegger supera a Hegel, o lo tergiversa en la desesperada lucha por demostrar cómo metafísicamente se construye una imagen del mundo estática y tecnologizada que oculta la verdadera manifestación del Ser.

Se perfila aquí un tema digno de tratar en un futuro, como lo es el concepto de historia y cultura que ambos manejan y que los comienza a diferenciar en este momento. Aunque el tema está latente en la conversación que abre Heidegger con un Hegel que dejó una obra abierta para su estudio, se detecta una diferencia abismal que marca las distintas conclusiones a las que llega cada uno de los autores mencionados en este artículo.

\section{Bibliografía}

De Towarnichi, Frederic; Palmier, Jean Michel (1981). Conversación con Heidegger. L'Express, núm. 954, 20, 26 de octubre de 1969 (Julio Díaz Báez, trad.). Revista Palos de la Crítica, núm. 4, abril setiembre 1981, recuperado de $<$ www.heideggeriana.com.ar>

GADAMER, Hans-Georg (1994). Hegel y Heidegger (versión castellana de Teresa Orduña y Manuel Garrido). Gadamer, Hans-Georg. La dialéctica de Hegel. Cinco ensayos hermenéuticos. Madrid: Cátedra, pp. 125-146.

Heidegger, Martín (1960). Sendas Perdidas (Holzwege; José Rovira Armengol, trad.) Buenos Aires: Losada.

Heidegger, Martín (1969). Hegel y los griegos. Edición de Revisión Fenomenológica. Serie Fundadores. Buenos Aires. Octubre. En <www.heideggeriana.com.ar>.

Wisser, Richard (1969). Entrevista a Martín Heidegger. Difundida el 24 de setiembre de 1969, en ocasión del octogésimo cumpleaños de Heidegger. Recuperado de $<$ www.heideggeriana.com.ar> 